\title{
A PREVALÊNCIA O PODER POTESTATIVO \\ DO EMPREGADOR EM FACE DO INCISO V \\ DO PARÁGRAFO ÚNICO DO ART. 53 DA LEI \\ DE DIRETRIZES E BASES DA EDUCAÇÃO \\ NACIONAL (LEI N. 9.394/ 1996)
}

André Araújo de Oliveira*

\section{RESUMO}

A Lei de Diretrizes e Bases da Educação Nacional, conhecida popularmente como LDB, Lei ${ }^{\circ}$. 9.394/1996, com o objetivo de demarcar a autonomia universitária achou por bem em condicionar a dispensa de professores à oitiva de colegiados internos da instituição de ensino. Por outro lado, isso representa limitação a um direito do empregador, qual seja, seu poder potestativo de proceder à dispensa de empregados desde que atendidas as premissas legais da legislação trabalhista. A proposta do presente artigo é demonstrar que nesse conflito deve prevalecer o direito do empregador de tal modo que seu poder de organização, nesse particular caracterizado pelo poder potestativo, não seja maculado.

Palavras-chave: LDB - dispensa - professor - limitação - poder potestativo - empregador.

\section{ABSTRACT}

The Law of Directives and Bases of National Education (9.394/1996), popularly known as LDB, in attempting to stake out the universities' autonomy, it conditioned the dismissal of a professor to the need of hearing the educational institution collegiate body. On the other

\footnotetext{
* Mestre em Direitos Difusos e Coletivos pela UNIMES - Universidade Metropolitana de Santos e Doutorando em Direito do Trabalho pela PUC - Pontifícia Universidade Católica de São Paulo; advogado e professor licenciado da Universidade Metodista de São Paulo - UMESP.
} 
hand, that condition is a limitation on the right of an employer to dismiss its employees provided that the legal premises of labor legislation are complied with. The purpose of this article is to demonstrate that in such conflict the employer's rights must prevail in a way which its power of organization, in particular, the one characterized by the potestative power, is not tainted.

\section{INTRODUÇÃO}

Sabe-se que o princípio da proteção norteia o direito do trabalho, de tal modo que várias garantias são direcionadas ao empregado frente ao empregador. Por outro lado, o empregador detém poderes para conseguir gerir de forma adequada a atividade empresarial desenvolvida.

Tais poderes são divididos em poder de organização, poder de controle e poder disciplinar.

Em muitas das vezes assegurar a plenitude do exercício de ambas as garantias pode não ser tarefa fácil. Na dúvida, prevalecerá a proteção ao trabalhador, daí a relevância de o empregador utilizar, com moderação e razoabilidade, os poderes que detém. Na eventualidade de ultrapassar seu limite, poderá ser repelido pelo Poder Judiciário de modo a prevalecer a correta aplicação da Lei.

O empregador possui o poder potestativo de dispensar seus empregados, porém esse poder não é absoluto. Em várias hipóteses interferiu o legislador para conferir maior proteção ao empregado, mesmo que isso representasse barreiras ao empregador em exercer seu encargo de optar pela manutenção ou não de determinado empregado por força de contrato de trabalho previamente pactuado.

$\mathrm{Na}$ área educacional, há previsão constitucional da autonomia universitária, importante valor assegurado a essas instituições. A autonomia, em que pese também não absoluta, permite que suas regras próprias ditem o direcionamento interno e na relação com a sociedade. De outro lado, a Lei de Diretrizes e Bases da Educação Nacional, de 1994, apontou 
no inciso $\mathrm{V}$ do parágrafo único do art. 53, previsão de que os Colegiados das universidades deliberem sobre a contratação e dispensa de professores.

Nesse sentido é que se propõe no presente artigo concluir pela legalidade ou não do referido dispositivo legal, considerando o conflito com a prerrogativa do empregador de exercer, plenamente, seu poder de comando, mesmo que se trate de instituição de ensino superior.

\section{O PRINCÍPIO DA PROTEÇÃO NO DIREITO DO TRABALHO}

A doutrina costuma apontar três desdobramentos do princípio da proteção no Direito do Trabalho, conforme passaremos a expor, em estreita síntese.

A primeira é a In dubio pro operário, pela qual, havendo dúvidas, a interpretação a ser conferida é aquela que favorece o trabalhador. Existindo situações desiguais na relação jurídica havida entre empregador e empregado, houve por bem tal princípio em privilegiar o hipossuficiente. Diferente de outros ramos do direito em que a preocupação precípua é a de garantir a igualdade entre as partes, temos cenário diverso no Direito do Trabalho. O ramo do Direito do Consumidor segue a mesma lógica, pois tem a premissa de proteger aquele que fica em situação desfavorecida na relação jurídica, especialmente no que tange à instrução probatória. A fonte dessa vertente confunde-se com o próprio histórico da relação trabalhista, em que as condições eram extremamente desfavoráveis ao empregado e o legislador acabou por encontrar na compensação legislativa uma forma de amenizar os impactos das distorções. Além do quesito dúvida, importante registrar que para invocar referido princípio há necessidade, também, da inexistência de oposição legislativa, ou seja, não pode o julgador afrontar a Lei para conferir benesses ao empregado em suas interpretações.

A segunda vertente é a da norma mais favorável, pela qual, como o próprio nome indica, na coexistência de mais de uma norma sobre determinada matéria, prevalece aquela 
que mais favorece o trabalhador. Primeiro ponto que merece destaque é o afastamento da hierarquia como baliza para identificar a norma a ser aplicada. Fosse essa a regra possivelmente não haveria necessidade da máxima da aplicação da norma mais favorável, pois prevaleceria a hierarquia. A norma mais favorável tem real importância justamente para afastar a hierarquia e se impor por si só.

Amauri Mascaro do Nascimento ${ }^{1}$ assinala:

"Ao contrário do direito comum, em nosso direito, entre várias normas sobre a mesma matéria, a pirâmide que entre elas se constitui terá no vértice não a Constituição Federal, ou a lei federal, ou as convenções coletivas de trabalho, ou o regulamento de empresa, de modo invariável e fixo. O vértice da pirâmide da hierarquia das normas trabalhistas será ocupado pela norma mais favorável ao trabalhador dentre as diferentes normas em vigor" .

Por fim, como terceira ideia do princípio da proteção no campo do Direito do Trabalho, tem-se a regra da condição mais benéfica. Refere-se à conquista do trabalhador de determinada condição, que passa a ser considerada o piso da relação e não pode mais retroceder. O próprio Tribunal Superior do Trabalho, pela Súmula $51^{2}$, tratou de materializar o princípio. As condições mais benéficas podem advir de uma obrigação imposta ao empregador, como no caso de

1 NAscimento, Amauri Mascaro. Curso de Direito do Trabalho. $20^{a}$ ed.. S.P.: Saraiva, 2000, pp. 291-292.

2 NORMA REGULAMENTAR. VANTAGENS E OPÇÃO PELO NOVO REGULAMENTO. ART. 468 DA CLT (incorporada a Orientação Jurisprudencial $\mathrm{n}^{\circ}$ 163 da SBDI-1) - Res. 129/2005, DJ 20, 22 e 25.04.2005

I - As cláusulas regulamentares, que revoguem ou alterem vantagens deferidas anteriormente, só atingirão os trabalhadores admitidos após a revogação ou alteração do regulamento. (ex-Súmula nº 51 - RA 41/1973, DJ 14.06.1973)

II - Havendo a coexistência de dois regulamentos da empresa, a opção do empregado por um deles tem efeito jurídico de renúncia às regras do sistema do outro. (ex-OJ no 163 da SBDI-1 - inserida em 26.03.1999)

6 - Revista do Curso de Direito da Faculdade de Humanidades e Direito, v. 14, n. 14, Edição Especial 2017 
previsão legal, mas também da iniciativa unilateral deste. Cabe ao empregador analisar cuidadosamente os beneficios e concessões extras conferidas aos empregados, pois uma vez estabelecidos, não poderão mais serem suprimidos. Exceção que merece especial atenção, mas que comporta ressalvas, é a de algum benefício temporário e vinculado a determinada condição que não mais subsiste. Nesse caso haveria possibilidade de justificar a supressão, porém com o risco de se adentrar na discussão da temporalidade, o que pode representar insegurança jurídica.

\section{O PODER DE DIREÇÃO DO EMPREGADOR}

Um dos requisitos da relação de emprego é o da subordinação. O empregado não detém autonomia para executar suas tarefas como bem entender, estando vinculado àquilo que é passado por sua chefia imediata, ou seja, cumpre suas obrigações na relação contratual conforme instruções recebidas de seu empregador. É o chamado poder de direção do empregador, insculpido no at. $2^{\circ}$ da CLT.

Como o empregador é quem dirige a atividade econômica, assumindo os riscos a ela inerentes, fica na condição de exigir de seus empregados, no campo da legalidade, que suas ordens sejam cumpridas.

O poder de direção do empregador subdivide-se em poder de organização, poder de controle e poder disciplinar.

Pelo poder de organização, tem o empregador a liberdade de se organizar da maneira mais adequada para atingir suas finalidades, fazendo uso, no caso de empregador empresário, dos diferentes fatures de produção, conforme ensina Fabio Ulhoa Coelho ${ }^{3}$ :

"A atividade dos empresários pode ser vista como a de articular os fatores de produção, que no sistema capitalista são quatro: capital, mão de obra, insumo e tecnologia".

3 COELho, Fábio Ulhoa. Manual de direito comercial: direito de empresa / Fábio Ulhoa Coelho. - 25 ed. - São Paulo: Saraiva, 2013. 
Pode, por exemplo, definir pela configuração societária mais adequada, se através de uma sociedade limitada, sociedade por ações, dentre outras.

Ainda, o poder de organização permite que o empregador escolha o ramo de sua atividade, desde que lícita, por óbvio.

A estrutura de governança é outra faculdade que cabe apenas ao empregador. Se mais enxuta ou com relevante investimento na área de pessoal, não é seara que compete a terceiros que não o próprio empregador.

Impor normas que devem ser observadas pelos empregados é mais uma materialização do poder de organização. Para poder exercer adequadamente o poder disciplinar, que será tratado em seguida, uma escorreita regulamentação das obrigações que se espera do empregado é fundamental para facilitar e justificar a adoção de medidas na hipótese de descumprimento. Não se tratando de infrações notórias, tal como preconizado no art. 482 da CLT, mesmo que a prova testemunhal ajude na identificação das instruções passadas, ter a regulamentação escrita é o cenário ideal para prevenir direitos. Nesse sentido é que muitas empresas, ao contratarem mão de obra, disponibilizam normativas internas, Códigos de Ética, normas sobre uso de tecnologia, tudo com o fito de receber do empregado uma correta contraprestação, mas também, de outro lado, poder punir quando há descumprimento do avençado. Tais normativas podem ser bilaterais, quando empregador e empregados acordam pela sua adoção, ou unilaterais, nos casos em que o empregador apenas impõe aquilo que deve ser observado.

Outra vertente do poder de direção do empregador refere-se ao poder de controle.

Trata-se de permitir a este exercer competente gerenciamento das atividades que serão executadas pelos empregados. Exemplo clássico apto a elucidar esta prerrogativa patronal é o de controlar a jornada de trabalho do empregado. Se há cumprimento do horário avençado, corretas marcações de 
ponto. Além disso, a entrega de resultados esperados e previamente alinhavados, está no escopo deste poder. Por óbvio, metas inalcançáveis e cobranças exageradas não encontram guarida nesta atuação patronal.

Por fim, este controle não pode invadir a esfera de intimidade dos empregados. Noutras palavras, sob argumento de estar exercendo encargo que lhe compete, não pode o empregador subtrair direitos que são inerentes aos empregados. Cita-se, exemplificativamente, conforme ensina Gustavo Filipe Barbosa Garcia ${ }^{4}$, a revista intima, a violação do sigilo de correspondência, interceptações telefônicas, salvo nesse último, em que haja respaldo judicial.

No que toca à revista íntima, tal não é admitida pelo nosso ordenamento jurídico, a teor do art. 373-A, inc. VI, da CLT. Mesmo que se refira às mulheres, o entendimento majoritário, já reforçado pela doutrina e jurisprudência, face ao princípio da isonomia, é que se aplica também aos homens. Exceção feita às revistas em bolsas, sacolas, armários, escrivaninhas dos empregados, desde que realizada de forma impessoal e aleatória, desprovida de contato físico com o empregado, as quais tem sido admitidas pela jurisprudência:

INDENIZAÇÃO POR DANOS MORAIS. REVISTA EM BOLSAS. A revista em bolsas, quando ocorre de forma impessoal e sem contato físico entre a pessoa que procede à revista e o empregado, não submete o trabalhador à situação vexatória, porquanto esse ato decorre do poder diretivo e fiscalizador da reclamada. Precedentes desta Corte superior. Recurso de revista não conhecido" (Proc.: RR - 1139500-64.2008.5.09.0016 Data de Julgamento: 08/02/2012, Relator Min. Lelio Bentes Corrêa, $1^{\text {a }}$ Turma, Data de Publicação: DEJT 24/02/2012).

"DANO MORAL. INDENIZAÇÃO. REVISTA VISUAL. Esta Corte tem reiteradamente entendido que a mera inspeção visual de bolsas, pastas e sacolas dos empregados, sem contato corporal

4 GARCIA, Gustavo Filipe Barbosa. Curso de Direito Processual do Trabalho, São Paulo, $2^{a}$ ed., São Paulo, Método: 2008, pág. 300. 
e ausente qualquer evidência de que o ato possua natureza discriminatória, não é suficiente para, por si só, ensejar reparação por dano moral. Precedentes" (Proc.: RR - 21490028.2009.5.09.0029. Data de Julgamento: 30/11/2011, Relator Min. Emmanoel Pereira, $5^{\text {a }}$ Turma, Data de Publicação: DEJT 09/12/2011).

DANOS MORAIS. REVISTA DE BOLSAS E SACOLAS. A revista consistente na verificação de bolsas e sacolas, sem nenhum contato físico e abuso por parte do empregador, não enseja o pagamento de indenização por danos morais" (Proc.: RR 384600-04.2007.5.09.0245. Data de Julgamento: 29/02/2012, Relator Min. Maria de Assis Calsing, $4^{\mathrm{a}}$ Turma, Data de Publicação: DEJT 02/03/2012).

Questão que apresentou certa divergência jurisprudencial diz respeito ao acesso a e-mail dos empregados. No caso, claramente há confronto entre dois direitos, quais sejam, o de controle, por parte do empregador, e o de sigilo de correspondência, pelo empregado. A doutrina e a jurisprudência posicionaram-se no sentido de validar a verificação, pelo empregador, das mensagens trocadas por seus empregados, mas acabou definindo algumas premissas. Duas delas, as mais importantes, é que seja apenas com relação ao e-mail institucional, caracterizado por aquele fornecido para o trabalho, de propriedade primeira do empregador, bem como que haja informação prévia aos empregados de que esse monitoramento acontece. Isso evitaria criar no empregado falsa expectativa de sigilo. É como se o e-mail que circula com o nome da empresa funcionasse como um "papel timbrado" desta, de modo que o empregador poderia ser responsabilizado pelo mau uso da ferramenta da organização.

Sérgio Pinto Martins ${ }^{5}$ assim analisou o tema:

\footnotetext{
5 MARTINS, Sérgio Pinto. Direito do trabalho. 21 ed. São Paulo: Atlas, 2005, p. 227.

10 - Revista do Curso de Direito da Faculdade de Humanidades e Direito, 
"O sigilo de comunicação de dados, como o e-mail, é também inviolável. Entretanto, essa regra não pode ser entendida de forma absoluta, principalmente diante da má-fé do empregado. Em casos de interesses relevantes, que podem, posteriormente, ser examinados pela Justiça, o empregador poderá monitorar os e-mails do empregado, desde que digam respeito ao serviço"

A jurisprudência vem se posicionando nesse sentido, conforme apontado acima, reforçando não existir legalidade no ausência de sigilo de e-mail tido por corporativo, sem falar na existência de norma interna prévia que afasta qualquer expectativa de liberdade ampla e irrestrita ao seu uso. É o que se percebe no julgado abaixo do Tribunal Superior do Trabalho ${ }^{6}$ :

AGRAVO DE INSTRUMENTO. RECURSO DE REVISTA. JUSTA CAUSA. PROVA ILÍCITA. Nenhum dos dispositivos declinados como violados, incluindo-se o art. $5^{\circ}$, XII, da $\mathrm{CF}$, disciplina a matéria inerente à ilicitude da prova para que se possa reputar violado. Além disso, a ilicitude da obtenção da prova pressupõe inobservância de norma disciplinadora, o que não sucedeu. Sob o prisma de violabilidade do sigilo dos e-mails, tampouco há falar em violação do art. $5^{\circ}$, XII, da CF, por se tratar de e-mail corporativo e não privado, meio de comunicação disponibilizado pelo empregador apenas para uso profissional conforme normas internas de conhecimento do empregado e com "expressa previsão de gravação e monitoramento do correio eletrônico, ficando alertado que o colaborador não deve ter expectativa de privacidade na sua utilização (item 6.1 - fl. 176)", conforme noticia o acórdão regional. JUSTA CAUSA. RECURSO DE REVISTA AMPARADO APENAS EM DIVERGENCIA JURISPRUDENCIAL. Sem valia as ementas transcritas, pois não informam a fonte de publicação. Súmula 337 do TST. Agravo de instrumento conhecido e desprovido.

Por fim, como terceiro tripé do poder de direção, tem-se o poder disciplinar. Trata-se de poder punir o empregado que

6 AIRR - 1461-48.2010.5.10.0003, Relator Ministro: Alexandre de Souza Agra Belmonte, Data de Julgamento: 25/02/2015, 3 ${ }^{\text {a }}$ Turma, Data de Publicação: DEJT 27/02/2015 
não cumpre com suas tarefas ou tem atitude incompatível com o que se espera da contraprestação do contrato de trabalho. Não se confunde, contudo, com sanções que remetem ao Poder Judiciário, possuindo limite de alçada no exercício das punições no âmbito interno da empresa. Pode, assim, exercer o poder disciplinar dentro do ambiente de trabalho, com consequências para este vínculo pré-estabelecido, mas na hipótese de dano causado em maior proporção, que requeira, por exemplo, punição criminal ou cível, esta que invada o patrimônio do trabalhador, deverá o empregador recorrer das vias judiciais próprias para ver atendido seu anseio.

As punições na esfera trabalhista podem ocorrer mediante aplicação de advertência, verbal ou escrita, suspensão, desde que limitada a 30 dias consecutivos, bem como, como medida drástica, a demissão por justa causa, conforme prevê o art. 482 da CLT.

Com relação à advertência verbal, possui nítido caráter pedagógico e pode inviabilizar a demonstração de comportamento reiterado a ensejar a aplicação de penalidade mais dura. Para este fim, não resta dúvidas de que a sanção escrita municia o empregador para prova em juízo na hipótese de novas faltas cometidas e, consequentemente, novas penalidades, pois evidenciará as várias oportunidades concedidas e não atendidas.

A gravidade da falta cometida é que determinará a pena aplicada. Se eventualmente existir um descompasso, ou seja, uma desproporcionalidade, poderá o Poder Judiciário ser instado a declarar a pena nula. Não cabe, nesse caso, uma adequação da pena, mas sim a sua nulidade. Pena mal aplicada por ser tida por pena nula (não existindo espaço para correção por parte do Judiciário).

Também não há necessidade de gradação de penalidades. Mesmo com histórico que nada desabone a conduta do obreiro, caso cometa falta grave poderá, apenas por esta conduta, ser desligado por justa causa. 
Quanto à possibilidade de penalidade pecuniária, esta apenas se sustenta em casos excepcionais, como expressamente previsto nas Leis 6.354/1976 e 9.615/1998 que regulamentam a atuação dos atletas profissionais.

\section{O PODER POTESTATIVO DO EMPREGADOR NA DISPEN-}

\section{SA DE EMPREGADOS}

Como reflexo do poder de direção do empregador, há o poder potestativo de deliberar pela dispensa de seus empregados, ou seja, pelo rompimento do contrato de trabalho pactuado previamente entre as partes.

A Constituição Federal não restringe o poder potestativo do empregador de rescindir o contrato de trabalho de professores universitários celetistas.

O artigo 207 da Carta Maior garante às universidades autonomia didático-científica, administrativa e de gestão financeira e patrimonial. No entanto, consoante jurisprudência do Supremo Tribunal Federal, tais autonomias universitárias devem ser interpretadas em consonância com o disposto no artigo 209 do texto constitucional.

Tem-se, assim, que a autonomia concedida às universidades para que possam realizar eficientemente suas atividades e atender a sua função social, encontra limites nos princípios e normas gerais previstos em nosso ordenamento jurídico.

Por conseguinte, todas as instituições privadas de ensino no País estão sujeitas ao cumprimento das normas gerais da educação nacional (Lei no 9.394/96 - estabelece as diretrizes e bases da educação nacional).

Nesse sentido e para adentrar pontualmente na discussão ora proposta, assim dispõe o inciso $\mathrm{V}$ do parágrafo único do artigo 53 da Lei 9.394/1996:

"Art. 53. No exercício de sua autonomia, são asseguradas às universidades, sem prejuízo de outras, as seguintes atribuições: $(\ldots$. 
Parágrafo único. Para garantir a autonomia didático-científica das universidades, caberá aos seus colegiados de ensino e pesquisa decidir, dentro dos recursos orçamentários disponíveis, sobre:

$(\ldots .$.

V - contratação e dispensa de professores;"

A jurisprudência majoritária do Colendo Tribunal Superior do Trabalho, fazendo a interpretação do artigo em comento, é firme no sentido de que a dispensa de professor universitário, vinculado a universidade particular, não depende de deliberação do respectivo órgão colegiado da instituição de ensino. Entende a Corte que o aludido dispositivo, não restringe o poder potestativo do empregador de rescindir o contrato de trabalho de professores universitários celetistas.

Frisa-se que a questão não reflete a criação de espécie de proteção contra a resilição contratual, com a consequente limitação ao poder potestativo do empregador, ou seja, não se está a tratar de garantia de emprego, mas apenas de fazer valer o princípio de gestão democrática colegiada, norteador do exercício das autonomias asseguradas às universidades pela Constituição da República e pela Lei de Diretrizes e Bases da Educação Nacional.

Assim, a deliberação do colegiado, numa última análise, poderia ocorrer quando tendente a observar os recursos orçamentários disponiveis para contratação e dispensa de professores. Isso não implica em dizer que para dispensar professor deverá haver deliberação do colegiado.

Destaca-se que não há nenhuma norma estabelecendo qualquer espécie de proteção contra a resilição contratual, com a consequente limitação ao direito do empregador de rescindir unilateralmente o contrato. Ou seja, não há vedação expressa a demissão de professor universitário sem justa causa.

Não há como conceber que a mantenedora de uma instituição de ensino, que pode contratar, não possa livremente 
exercer o direito de dispensar um empregado, sem justa causa. É um absurdo gritante tendo em vista que a Constituição Federal incentiva a integração econômica e a livre iniciativa, em respeito à propriedade privada. Isso porque, na iniciativa privada, os empregadores são livres para contratar e distratar, sem justa causa.

A alegação de que para se efetivar uma demissão sem justa causa deve uma instituição de ensino privada recorrer aos colegiados internos, que são compostos por pares daquele que será demitido, não faz qualquer sentido. Não se pode transferir a administração e o risco econômico e patrimonial para colegiados internos que não tem esta competência, que é exclusiva do seu representante legal. Isto confronta com o poder de comando conferido ao empregador, máxime em razão do colegiado interno não assumir nenhuma responsabilidade de administração.

Esse tem sido o entendimento adotado pelo Tribunal Superior do Trabalho:

RECURSO DE REVISTA EM FACE DE DECISÃO PUBLICADA ANTES DA VIGÊNCIA DA LEI No 13.015/2014. REINTEGRAÇÃO AO EMPREGO. PROFESSOR DE INSTITUIÇÃO PARTICULAR DE ENSINO. NULIDADE DO ATO NÃO CONFIGURADA. Esta Corte uniformizadora já consolidou o entendimento de que as disposições insertas no parágrafo único do artigo 53 da Lei $\mathrm{n}^{\circ}$ 9.394/96 não objetivam estabelecer proteção contra a despedida dos professores universitários, porquanto apenas dão efetividade à previsão contida no artigo 207 da Constituição Federal (autonomia didático-científica, administrativa e de gestão financeira e patrimonial), de modo que inexiste óbice ou necessidade de deliberação de órgão colegiado para que o empregador exerça o seu direito potestativo de dispensar, imotivadamente, o professor contratado sob o regime da CLT. Decisão regional que merece reparo. Recurso de revista de que se conhece e a que se dá provimento.

( RR - 619100-67.2009.5.09.0011, Relator Ministro: Cláudio Mascarenhas Brandão, Data de Julgamento: 17/05/2017, $7^{\text {a }}$ Turma, Data de Publicação: DEJT 02/06/2017) 
AGRAVO DE INSTRUMENTO DO AUTOR. RECURSO DE REVISTA INTERPOSTO SOB A ÉGIDE DAS LEIS N ${ }^{\circ} 13.015 / 2014$ E 13.105/2015 - DESCABIMENTO. 1. NULIDADE. NEGATIVA DE PRESTAÇÃO JURISDICIONAL. Quando a decisão se mostra bem lançada, com estrita observância das disposições dos arts. 93, IX, da Constituição Federal, 458 do CPC e 832 da CLT, não se cogita de nulidade, por negativa de prestação jurisdicional. 2. INDENIZAÇÃO POR DANO MORAL. VALOR ARBITRADO. A indenização por dano moral guarda conteúdo de interesse público. O valor fixado deve observar a extensão do dano sofrido, o grau de comprometimento dos envolvidos no evento, os perfis financeiros do autor do ilícito e da vítima, além de aspectos secundários pertinentes a cada caso. Incumbe ao juiz fixá-lo com prudência, bom senso e razoabilidade. 3 . REINTEGRAÇÃO. PROFESSOR. DISPENSA IMOTIVADA. A jurisprudência desta Corte é no sentido de que é desnecessária a motivação ou procedimento específico para que a instituição de ensino particular exerça o direito potestativo de demitir seus professores. 4. REDUÇÃO DE CARGA HORÁRIA. Estando a decisão em conformidade com a OJ 244 da SBDI-1/TST, o art. 896, $\S 7^{\circ}$, da CLT e a Súmula 333/TST constituem óbice ao processamento do recurso de revista. Agravo de instrumento conhecido e desprovido.

( AIRR - 2090600-10.2006.5.09.0014, Relator Ministro: A1berto Luiz Bresciani de Fontan Pereira, Data de Julgamento: 24/05/2017, 3a Turma, Data de Publicação: DEJT 02/06/2017)

RECURSO DE REVISTA. PROFESSOR. INTERVALO ENTRE AULAS. RECREIO. TEMPO À DISPOSIÇÃO DO EMPREGADOR. Esta Corte Superior já fixou o entendimento de que o intervalo entre aulas conhecido como "recreio" constitui tempo à disposição do empregador, nos termos do art. $4^{\circ}$ da CLT, devendo, pois, integrar a jornada de trabalho do professor. Recurso de revista conhecido e provido. PROFESSOR DE UNIVERSIDADE PARTICULAR. DISPENSA. DESNECESSIDADE DE APROVAÇÃO PELO CONSELHO DIRETOR. A jurisprudência predominante no Tribunal Superior do Trabalho firmou-se no sentido de que a regra estabelecida no art. 53, parágrafo único, inciso $\mathrm{V}$ da Lei 9.394/96 não consiste em uma restrição ao direito potestativo do empregador, de modo a caracterizar uma estabilidade provisória no emprego do professor, em razão da autonomia 
garantida constitucionalmente às universidades, sendo desnecessária a prévia aprovação pelo Conselho Universitário para a demissão de professores. Há precedentes. Recurso de revista não conhecido.

( RR - 2787400-77.2008.5.09.0015, Relator Ministro: Augusto César Leite de Carvalho, Data de Julgamento: 09/11/2016, 6 Turma, Data de Publicação: DEJT 11/11/2016)

PROFESSOR - DISPENSA - PROTEÇÃO AO EMPREGO - LEI N. ${ }^{\circ}$ 9.394/96 - PROVIMENTO. Os princípios constitucionais invocados, a Lei n. ${ }^{\circ} 9.394 / 96$, no art. 53, parágrafo único, ou o Regimento Interno da Reclamada não asseguram a estabilidade pretendida, do professor, no cargo ou função. Recurso de Revista conhecido parcialmente e provido-. (TST, RR 7710/2005008-09-00, Ac. 8. ${ }^{a}$ Turma, Rel. Min. Maria Cristina Peduzzi, publicado no DEJT - 18/12/2009.)

NULIDADE DA DISPENSA - REINTEGRAÇÃO. A norma prevista no art. 53, parágrafo único, inciso V, da Lei 9.394/1996, tem o caráter genérico a ser observado no planejamento orçamentário das instituições de ensino superior, visando garantir a autonomia didático-científica das universidades, mas não tem o condão de limitar o poder potestativo do empregador para contratar ou dispensar professores. Assim, a resilição contratual de professores nas universidades particulares, observadas as regras da CLT, não está submetida à deliberação de colegiados de ensino superior.- (TST, RR 14300-15.2006.5.15.0001, Ac. 7. ${ }^{\mathrm{a}}$ Turma, Rel. Juíza Convocada Maria Doralice Novaes, publicado no DEJT - 8/10/2010.)

RECURSO DE REVISTA - ENSINO SUPERIOR - NULIDADE DA DISPENSA - REINTEGRAÇÃO - ART. 53 DA LEI N ${ }^{\circ}$ 9.394/1996 A norma prevista no art. 53, parágrafo único, inciso $\mathrm{V}$, da Lei 9.394/1996, não tem o condão de limitar o poder potestativo do empregador para contratar ou dispensar professores. Precedentes. (RR - 169700-88.2009.5.08.0008, 8 ${ }^{a}$ Turma, Rel. Min. Carlos Alberto Reis de Paula, D.J. de 8/4/2011)

-REINTEGRAÇÃO - DEMISSÃO. PROFESSOR UNIVERSITÁRIO - DESNECESSIDADE DE MOTIVAÇÃO. O Regional entendeu que a legislação federal de ensino 
superior e as normas da reclamada asseguravam a estabilidade dos professores universitários. Extrai-se das disposições do artigo 53 da Lei n. ${ }^{\circ}$ 9.394/96, citado na decisão atacada, que se objetiva regulamentar a autonomia constitucionalmente garantida às universidades, no intuito de impedir as ingerências externas nas diretrizes por elas traçadas. Todavia, o objetivo da norma não é impor restrições ao poder potestativo do empregador de rescindir determinado contrato de trabalho por motivos alheios às questões de política educacional e administrativa da instituição de ensino. Precedentes. Conhecido e provido- (TST-RR-91700-40.2005.5.09.0670, Rel. Min. Emmanoel Pereira, 5 ${ }^{\text {a }}$ Turma, DEJT de 12/03/10).

\section{CONCLUSÃO}

Considerando o acima exposto, outra não pode ser a conclusão de que o ato de dispensa do professor universitário, que não detém garantia específica de emprego, é direito potestativo do empregador, como ocorre em qualquer outra atividade econômica, ao menos enquanto não for editada a lei complementar mencionada no artigo $7^{\circ}$, I, da Constituição Federal.

Assim, no exercício de sopesar direitos, deve prevalecer a liberdade de o empregador exercer seu comando interno de direção em detrimento da norma limitadora prevista no inciso V, parágrafo único, do art. 53 da Lei $n^{\circ}$. 9.394/1996.

\section{REFERENCIAS}

BARROS, Alice Monteiro de. Curso de Direito do Trabalho. 2. ed. São Paulo: LTr, 2006.

COELHO, Fábio Ulhoa. Manual de direito comercial: direito de empresa / Fábio Ulhoa Coelho. - 25 ed. - São Paulo: Saraiva, 2013.

DELGADO, Maurício Godinho. Curso de Direito do Trabalho. São Paulo: LTr, 2012.

GARCIA, Gustavo Filipe Barbosa. Curso de Direito Processual do Trabalho, São Paulo, $2^{a}$ ed., São Paulo, Método: 2008.

MARTINS, Sérgio Pinto. Direito do trabalho. 21 ed. São Paulo: Atlas, 2005, p. 227.

NASCIMENTO, Amauri Mascaro. Curso de Direito do Trabalho. 20 a ed.. S.P.: Saraiva, 2000, pp. 291-292. 


\section{A PREVALÊNCIA O PODER POTESTATIVO DO EMPREGADOR EM FACE DO \\ INCISO V DO PARÁGRAFO ÚNICO DO ART. 53 DA LEI DE DIRETRIZES \\ E BASES DA EDUCAÇÃO NACIONAL (LEI No. 9.394/ 1996)}

NASCIMENTO, Amauri Mascaro. Iniciação ao direito do Trabalho. 2. ed., São Paulo: Saraiva, 2007.

http://www.tst.jus.br/sumulas, acesso em 01/06/2017.

http://www.tst.jus.br/jurisprudencia , acesso em 25/05/2017. 